\title{
Low Dose Tedd Affects Membrane Bound Ion Dependent Atpases in Mice Liver
}

\author{
${ }^{1}$ Jyoti Jigyasi, Rahul Kundu ${ }^{2}$ \\ ${ }^{1,2}$ Department of Biosciences, Saurashtra University, Rajkot-360005, Gujarat State, India,
}

\begin{abstract}
Present communication reports in vivo dose and duration dependent effects of a dioxin $(2,3,7,8$ $T C D D)$ on few membrane bound ion dependent ATPases of mice hepatocytes. Two hypotheses were tested in this study. Separate groups of mice were exposed to two very low sublethal doses $(0.004 \mathrm{mg} / \mathrm{kg} \mathrm{bw}, 0.04 \mathrm{mg} / \mathrm{kg}$ bw) of TCDD by daily oral administration for 2, 4 and 6 days. Separate control groups were also maintained which received only corn oil, the vehicle. The results indicated a significant exposure duration dependent alterations in the membrane ATPases. No clear dose dependent effects were observed. The results suggested that the observed alteration in the enzyme activity was possibly due to the oxidative stress generated by TCDD on the membrane-bound ion-dependent ATPases. The results also indicated that the membrane bound hydrophilic ATPases were indeed influenced by the hydrophobic TCDD. However, the effects were possibly indirect through complex chain of reactions exhibited by the cells under in vivo conditions. ROS was suspected to have played an important role in the alterations of membrane transport systems and permeability which caused cellular injury, and thereby exhibiting exposure duration dependent effects.
\end{abstract}

Keywords: ATPases, Dose \& Duration dependent effects, liver, mice, TCDD

\section{Introduction}

2,3,7,8 tetra chloro di benzo-p-Dioxin (TCDD) has received great attention in recent times because its presence in the environment may cause adverse effects to human health. Living organisms including man are mostly exposed to persistent organic pollutants, including contaminants that have either dioxin like or nondioxin like properties like many PCBs, pesticides. Over 90 Percent of human being are exposed to the dioxins occurs through the diet essentially with fats, dairy products and milk. Hepatotoxicity caused by TCDD was observed in the species experimented with However, little variation was reported in the species sensitivity to the TCDD [1]. Significant positive relationship between the toxicity caused by TCDD in different mammals and total body fat content (\%) was observed in some studies. ATPases are known to be regulating the ions and metabolites across the plasma membrane in order to maintain the normal physiological and biochemical functions of the cells. A dose dependent inhibition in plasma membrane ATPase accompanied by the lowered biliary excretion was observed in the TCDD treated rats [2]. The hepatotoxicity of TCDD included morphological and biochemical changes including induced hyperplasia and hypertrophy of liver parenchymal cells [1]. The earlier studies reported that TCDD treated rats had different protein profiles of hepatic plasma membrane from those of untreated controls [3]. In vivo exposure of TCDD was reported to affect a number of physiologically important components of rat liver plasma membrane [4]. Going through the literature it was evident that studies on the toxicity of dioxin on the hepatic cell membrane systems in general and ATPase system in particular are rare. Therefore, the present communication tests two hypotheses that (a) dose and duration dependent in vivo exposure of TCDD would affect the hydrophilic membrane-bound ion dependent ATPases of the liver cells even at a very low concentration, and (b) the observed response could be a direct effect of the toxicant on the membrane bound ion dependent enzymes systems.

\section{Materials And Methods}

\subsection{Animals}

Adult female Swiss albino mice, around 3 months of age and weighing $30 \pm 5 \mathrm{~g}$, were used for the entire study. The animal groups were provided with ad libitum commercially available rodent diet and water and kept under highly hygienic conditions in the animal house facilities as approved by the CPCSEA, India. The mice were kept under controlled humidity, temperature $\left(25 \pm 2{ }^{\circ} \mathrm{C}\right)$ and diurnal cycle of $14: 10 \mathrm{~h}$. The infected and moribund animals were removed or not included for experimental study. All experiments were conducted according to ethical norms provided by CPCSEA India (CPCSEA/CH/RF/ACK-2003).

\subsection{Chemicals}

2,3,7,8 TCDD was procured from Sigma- Aldrich chemicals Pvt. Ltd. (CAS No. 1746-01-6). All other chemicals used for this study were of analytical grade. 


\subsection{Experimental Design and Treatment}

In the present study, a total of 81 adult female mice were used in different groups. The intoxication was done by oral administration of 2,3,7,8 TCDD (Sigma) in 0.004 and $0.04 \mathrm{mg} / \mathrm{kg}$ body weight/day doses, dissolved in corn oil (Sigma) for three different exposure durations (2, 4 and 6 days). Separate control groups were also maintained that received a similar daily dose of vehicle (corn oil) only. The selection of doses were based on the $\mathrm{LD}_{50}$ of TCDD in mice along with the minimum required dose reported to be toxic to human and the availability of TCDD and its residue in nature.

\subsection{Tissue Preparation and Enzyme Assay}

After toxic exposure, the liver was quickly harvested and washed in ice cold Sucrose-EDTA-Imidazole (SEI) buffer. Fixed amount of liver tissue was homogenized in a Potter-Elvehjem glass homogenizer at $4^{\circ} \mathrm{C}$ in SEI buffer to make a $10 \%$ (w/v) tissue concentration. Tissue extraction and Enzyme assay of Total ATPase, $\mathrm{Na}^{+}-\mathrm{K}^{+}, \mathrm{Ca}^{++}, \mathrm{Mg}^{++}, \mathrm{CaHCO}_{3}{ }^{-}$and $\mathrm{MgHCO}_{3}{ }^{-}$ATPases were done by the method of Zaugg [5] with appropriate modifications [6,7]. Resulting inorganic phosphate was measured by the method of Fiske and Subbarow [8]. Protein content in the tissue extract was estimated by the method of Lowry et al, [9] using crystalline bovine serum as standard.

\subsection{Statistical Analysis}

The obtained data were subjected to various statistical analyses for their cumulative acceptability and for testing the hypotheses formulated. A single factor ANOVA was employed for the significance in the variations between control and doses. A two-way nested ANOVA was employed to check the significance in the variations between different doses and amongst different exposure durations. In addition to those tests, Student's t-test was employed for the significance in the variations between control and each duration within a given dose. All statistical procedures were done as per Sokal and Rohlf [10].

\section{Results}

Results of the present investigation showed variations in the hepatocyte membrane ATPases after exposure to different doses of 2,3,7,8 TCDD. The specific activity of Total ATPase showed stimulation in 0.004 $\mathrm{mg} / \mathrm{kg}$ bw/day group. In $0.04 \mathrm{mg} / \mathrm{kg}$ group, an initial inhibition after 2 days of exposure was observed but showed stimulation after 4 and 6 days (Fig. 1a). The activity of $\mathrm{Na}^{+}-\mathrm{K}^{+}$ATPase showed high stimulation in all exposure durations in the lower dose group, whereas, the higher $(0.04 \mathrm{mg} / \mathrm{kg}$ bw/day $)$ dose showed highest inhibition after 2 and 6 days of exposure durations (Fig. 1b). The specific activity of $\mathrm{Ca}^{++}$ATPase showed high stimulation over increasing exposure durations in the lower dose group. However, in higher dose group, slight stimulation after 2 and 4 days of exposure was observed followed by inhibition after 6 days of exposure duration (Fig. 1c). The specific activity of $\mathrm{Mg}^{++}$ATPase showed high stimulation with increasing exposure duration in the lower dose group. In high dose group however, a slight stimulation was observed after 2 and 6 days of exposure durations followed by an inhibition after 4 days of exposure duration (Fig. 1d). The specific activity of $\mathrm{Ca}^{++} \mathrm{HCO}_{3}{ }^{-}$ATPase showed stimulation in all exposure duration in the lower dose group. In higher dose group, the activity showed slight inhibition after 2 and 4 days of exposure duration but showed stimulation after 6 days of exposure duration (Fig. 1e). The specific activity of $\mathrm{Mg}^{++} \mathrm{HCO}_{3}{ }^{-}$showed stimulation in all exposure durations in the lower dose group but an inhibitory trend was observed in all exposure durations of the higher dose group (Fig. 1f).

\section{Discussion}

In the present investigation, the activities of membrane bound ATPases in TCDD treated mice liver were showed significant variations from the untreated control. The purpose of this study was to have an estimate that how severely TCDD induced changes in the plasma membrane. It was reported earlier that the protein profile of rat liver plasma membrane was altered by TCDD treatment [3]. Liver, being the largest gland and main detoxifying organ of the body is a principal location for various metabolic processes. Since the ATPases are responsible for trans-membrane movements of ions, it is possible that the dioxin affected the transport channels of the hepatocytes cells by altering the enzyme activity [7]. The results of two factors ANOVA showed exposure duration dependent effects of TCDD in liver tissue of mice (Table 1). However, the t-test between control and total ATPase activity showed significant differences in all exposure durations (Table 2). The observed results expressed the possibility that TCDD bind with cytosolic receptor and transported into nucleus [11]. The resultant expression of some gene, rather than the lipophilic TCDD directly interacted with lipophobic membrane channel proteins [12]. Though the exact mechanism is not clear at this point, the reduction of $\mathrm{Na}^{+}-\mathrm{K}^{+}$ -ATPase activity observed after administration of TCDD was possibly not a direct influence of the toxicant with the enzyme itself but due to indirect effects through chain of reactions in the cytoplasm [2]. TCDD exposure 
caused changes in liver structure and functions and an increase in liver size had been reported in murine investigations [13]. These studies indicated that the degree of enzyme inhibition or stimulation depended upon the type of ATPase, tissue, animal species, and the toxic compound used. $\mathrm{Ca}^{2+}$ ATPase and $\mathrm{Na}^{+} \mathrm{K}^{+}$ATPase are involved in the transport of $\mathrm{Ca}^{2+}$ and $\mathrm{Na}^{+}$across the plasma membrane respectively. In this study, the observed changes in the enzymatic activity were possibly due to exposure duration dependent effects. ATPase is known to be regulating different ions and metabolites across the membrane, in order to maintain the physiological requirement of the cell. It may be possible that the observed disturbances of $\mathrm{Na}^{+}-\mathrm{K}^{+}$ATPase affected $\mathrm{Na}-\mathrm{K}$ pump, causing uncontrollable entry of $\mathrm{Na}^{+}$into the cell along the concentration gradient, followed by water molecules along the osmotic gradient [14]. These twin actions possibly caused cell swelling and a possible membrane rupture [15].

In the present study, high significant differences in the higher dose group were observed in all other enzymes except $\mathrm{Na}^{+}-\mathrm{K}^{+}$ATPase and $\mathrm{Ca}^{2+}$ ATPase (Table 2). In case of $\mathrm{Na}^{+}-\mathrm{K}^{+}$activity, the significance difference showed in 4 and 6 days of exposure durations. In case of $\mathrm{Ca}^{2+}$ ATPase result of $\mathrm{t}$-test between control and treatment lowest group showed highest significant variation in 4 days of exposure duration. $\mathrm{In}_{\mathrm{Mg}}{ }^{2+}$ ATPase activity showed drastic changes in all exposure duration whilst the highest significant variation showed in 2 days of exposure duration. In case of $\mathrm{Ca}^{2+}, \mathrm{HCO}^{-}$ATPase activity showed significant variation after 4 days of exposure duration in both the dose groups. In $\mathrm{Mg}^{2+} \mathrm{HCO}_{3}^{-}$ATPase the enzymatic activity showed significant variation after 6 days of exposure duration in lower dose group but, in the higher dose group, significant variations were observed after 2 days of exposure duration. The result of single factor ANOVA between control and toxicated group indicated highly significant variation in all exposure durations (Table 3). It may be possible that the enzyme might have accumulated in the intracellular space due to the altered membrane permeability or leakage in the affected membrane. The results of the present study obviously indicated an indirect effect of TCDD on the membrane channel proteins. As it is understood, the mechanism involved in the altered activity of the enzymes studied is not a direct dose-response to the individual enzyme proteins. The dioxin compounds are not specific for specific type of ATPase enzyme, thereby suggested that possibly many factors may be involved in the toxic effects observed [7]. Similarly, the degree of lipophilicity cannot explain the observed alteration in enzyme activity, due to the reported insensitivity of rat liver mitochondrial $\mathrm{Mg}^{2+}$ ATPase to the highly lipophilic compound Mirex [16].
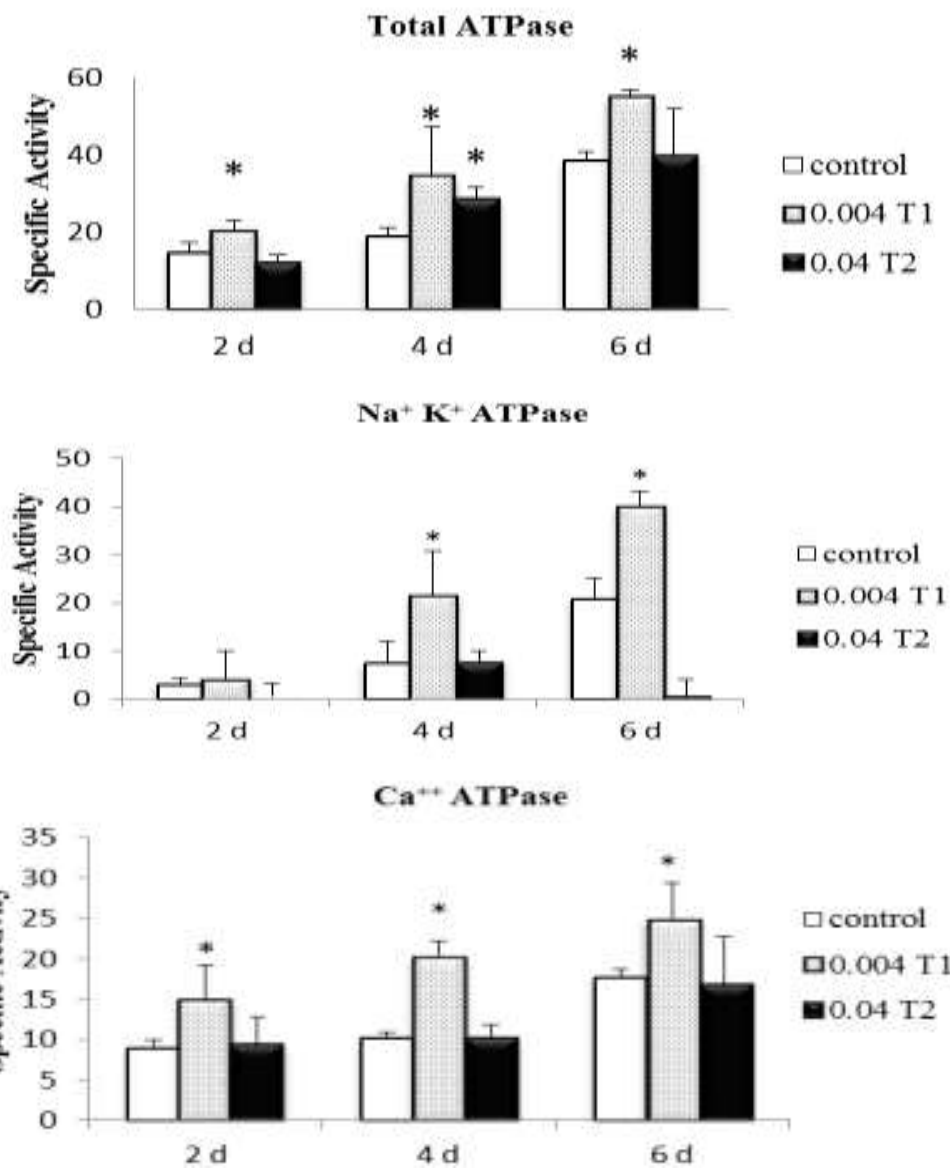
$\mathrm{Mg}^{++}$ATPase


Fig. 1. Dose and duration dependent changes in the specific activities of different ATPases after TCDD intoxication. The error bars represent standard deviation over mean values. * represents statistical significance at $\mathrm{P}=0.05$ level.

TABLE 1. Results of Two-factor ANOVA between control and toxicated groups. The test clearly show no dose dependent effects, but a highly significant exposure duration dependent effects.

\begin{tabular}{|l|c|c|c|c|c|c|}
\hline & TOTAL & $\mathbf{N a}^{+}-\mathbf{K}^{+}$ & $\mathbf{C a}^{2+}$ & $\mathbf{M g}^{2+}$ & $\mathbf{C a}^{2+} \mathbf{H C O}_{3}^{-}$ & $\mathbf{M g}^{2+} \mathbf{H C O}_{3}^{-}$ \\
\hline Amongst Doses & 0.25 & 0.73 & 0.10 & 0.26 & 0.46 & 0.16 \\
\hline Within Duration & $17.89^{* *}$ & $31.42^{* *}$ & $10.55^{* *}$ & $18.43^{* *}$ & $12.00^{* *}$ & $10.06^{* *}$ \\
\hline
\end{tabular}

$*$ Significance at $\mathrm{P}=0.05(\mathrm{~F}$ crit $(\mathrm{dF}=3,8)=3.008)$

** Significance at $\mathrm{P}=0.05(\mathrm{~F}$ crit $(\mathrm{dF}=8,35)=2.35)$

TABLE 2. Results of Student's ' $\mathrm{t}$ '-test between control and individual exposure durations within each dose.

\begin{tabular}{|c|c|c|c|c|c|c|c|c|c|c|c|c|}
\hline & \multicolumn{2}{|c|}{ TOTAL } & \multicolumn{2}{|c|}{$\mathrm{Na}^{+}-\mathrm{K}^{+}$} & \multicolumn{2}{|c|}{$\mathrm{Ca}^{2+}$} & \multicolumn{2}{|c|}{$\mathrm{Mg}^{2+}$} & \multicolumn{2}{|c|}{$\mathrm{Ca}^{2+} \mathrm{HCO}_{3}^{-}$} & \multicolumn{2}{|c|}{$\mathrm{Mg}^{2+} \mathrm{HCO}_{3}^{-}$} \\
\hline & $\begin{array}{c}0.004 \\
\mathrm{mg}\end{array}$ & $\begin{array}{c}0.04 \\
\mathrm{mg}\end{array}$ & $\begin{array}{c}0.004 \\
\mathrm{mg}\end{array}$ & $\begin{array}{c}0.04 \\
\mathrm{mg}\end{array}$ & $\begin{array}{c}0.004 \\
\mathrm{mg}\end{array}$ & $\begin{array}{c}0.04 \\
\mathrm{mg}\end{array}$ & $\begin{array}{c}0.004 \\
\mathrm{mg}\end{array}$ & $\begin{array}{c}0.04 \\
\mathrm{mg}\end{array}$ & $\begin{array}{c}0.004 \\
\mathrm{mg}\end{array}$ & $\begin{array}{c}0.04 \\
\mathrm{mg}\end{array}$ & $\begin{array}{c}0.004 \\
\mathrm{mg}\end{array}$ & $\begin{array}{c}0.04 \\
\mathrm{mg}\end{array}$ \\
\hline $\begin{array}{l}2 \\
\mathrm{~d}\end{array}$ & $2.93 *$ & 1.80 & 0.53 & 1.56 & $2.78 *$ & 0.26 & $3.18^{*}$ & $3.45^{*}$ & 2.07 & 0.56 & 2.08 & $6.24 *$ \\
\hline $\begin{array}{l}4 \\
\mathrm{~d}\end{array}$ & $2.39 *$ & $4.88 *$ & $2.71 *$ & 0.16 & $9.67 *$ & 0.06 & $2.79 *$ & $5.62 *$ & $\begin{array}{c}23.59 \\
*\end{array}$ & $9.92 *$ & 1.92 & 1.06 \\
\hline $\begin{array}{l}6 \\
\mathrm{~d} \\
\end{array}$ & $9.22 *$ & 0.20 & $7.05 *$ & 0.07 & $3.07 *$ & 1.22 & 1.49 & $2.61 *$ & 1.25 & 0.46 & $7.26^{*}$ & 0.99 \\
\hline
\end{tabular}

*Significance at $\mathrm{P}=0.05($ T crit.$=2.447)$ 
TABLE 3. Results of single-factor ANOVA between individual exposure durations within each group. Results show the gross significant variations in the enzyme activity amongst each dose group and within exposure

\begin{tabular}{|c|c|c|c|c|c|c|}
\hline & TOTAL & $\mathbf{N a}^{+}-\mathbf{K}^{+}$ & $\mathbf{C a}^{2+}$ & $\mathbf{M g}^{2+}$ & $\mathbf{C a}^{2+} \mathbf{H C O}_{\mathbf{3}}{ }^{-}$ & $\mathbf{M g}^{\mathbf{2}^{+}} \mathbf{H C O}_{\mathbf{3}}{ }^{-}$ \\
\hline CONTROL & 97.98 & 24.36 & 106.20 & 76.30 & 63.34 & 51.25 \\
\hline $\mathbf{0 . 0 0 4}$ & $20.08^{*}$ & $58.47^{*}$ & $6.98^{*}$ & $5.95^{*}$ & 1.25 & $7.35^{*}$ \\
\hline $\mathbf{0 . 0 4}$ & $14.29^{*}$ & 1.27 & 3.75 & $27.81^{*}$ & $17.43^{*}$ & $17.02^{*}$ \\
\hline
\end{tabular}

*Significance at $\mathrm{P}=0.05(\mathrm{~F}$ crit. $=4.25)$

\section{Conclusion}

The results indicate a predominant exposure duration dependent alterations in the specific activity of membrane ATPases. These effects were presumably indirect through complex chain of reactions exhibited by the cells when subjected to the toxic stress. TCDD being lipophilic possibly enters into the cell by dissolving itself into the plasma membrane. It is possible that TCDD which remains free and unattached with receptors in the cytosol may react with other compounds around and might have evoked responses which were responsible for alteration in the membrane transport mechanisms. The observed effects caused by exposure durations were indicative of indirect effect of TCDD to these enzyme systems in in vivo conditions. ROS, a byproduct of cellular metabolism of low concentration Dioxin, might have played an important role in alterations of membrane transport systems and permeability which caused liver injury.

\section{Acknowledgement}

Authors are thankful to UGC, Govt. of India, New Delhi, for supporting this study through its DSA / CAS Programme. UGC is also thankfully acknowledged for a Meritorious Research Fellowship awarded to senior author.

\section{References}

[1] U.S. EPA, Health Assessment Document for 2,3,7,8-Tetrachlorodibenzo-p-Dioxin (TCDD) and Related Compounds, Office of Health and Environmental Assessment, Office of Research and Development, United States Environmental Protection Agency, Washington, D.C., 1,1994,3-17.

[2] Peterson R.E, Madhukar B.V, Yang K.H, Matsumura F, Depression of adenosine triphosphatase activities in isolated liver surface membranes of 2,3,7,8 tetrachloro dibenzo-p-dioxin, In: Khan MAQ, Stanton RH, editors. Toxicology of halogenated hydrocarbons: Health and ecological effects, New York : Pergamon Press, 1979, 133-145.

[3] Brewster D.W, Madhukar B.V, Matsumura F, Influence of 2,3,7,8 TCDD on the protein composition of the plasma membrane of hepatic cells from the rat. Biochemical and Biophysical Research Communication. 107, 1982, 68-74.

[4] Birnbaum L.S, Tuomisto J, Non-carcinogenic effects of TCDD in animals. Food Additives and Contaminants. 17, $2000,275-288$.

[5] Zaugg W.S, A simplified preparation for ATPase determination in gill tissue. Canadian Journal of fisheries and aquatic sciences, 39, 1982, 215-217.

[6] Lakshmi R, Kundu R, Thomas E, Mansuri A.P, Mercuric chloride induced inhibition of different ATPases in the intestine of mudskipper, Boleophthalmus dentatus. Ecotoxicology and Environmental Safety, 21, 1991, 121 - 125.

[7] Pathak S, Kundu R, Short-term PCB (Aroclor 1254) toxicity on few phosphatases in mice brain. Dose Response. 2011 : (doi:10.2203/dose-response.10-037.Kundu).

[8] Fiske C.F, Subbarow Y, The colorimetric determination of phosphorus. Journal of Biological Chemistry. 66, 1925 375-400.

[9] Lowry O.H, Rosebrough N.J, Farr A.L, Randall R.J, Protein measurement with the Folin-phenol reagent. Journal of Biological Chemistry, 193, 1951, 265-275.

[10] Sokal R.R, Rohlf F.J, Biometry. San Francisco. WH Freeman and Company. 1969.

[11] Poland A, Kinde A. 2,3,7,8 Tetrachlorodibenzo-p-dioxin: environmental contaminants and molecular probe. Federation Proceedings, 35,1976, 2404-2411.

[12] Nebert D.W, Genetic differences in the induction of monooxygenase activities by polycyclic aromatic compounds, Pharmacology and Therapeutics, 6,1979, 395-417.

[13] Agency for Toxic Substances and Disease Registry (ATSDR), Toxicological profile for chlorinated dibenzo-p-dioxins. U.S. Department of Health and Human Services, Public Health Service, Atlanta, GA. 2000.

[14] Thaker J, Chhaya J, Nuzhat S, Mitral R, Mansuri AP, Kundu R, Effects of Chromium (VI) on some ion dependent ATPases in gills, kidney and intestine of a coastal teleost, Periophthalmus dipes. Toxicology, 112, 1996, 237-244.

[15] Kundu R, Lakshmi R, Mansuri A.P, The entry of mercury through the membrane: An enzymological study using a tolerant fish Boleophthalmus dentate. Proceedings of the Academic Environmental Biology 1,1992, 1-6.

[16] Desaiah D, Ho I.K, Mehendale H, Effects of kepone and mirex on mitochondrial Mg- ATPase activity in rat liver. Toxicology and Applied Pharmacology, 39, 1977, 219-228. 